\title{
A MENSURAÇÃO DO CAPITAL INTELECTUAL: ANÁLISE DO MODELO ADEQUADO À PRÁXIS ORGANIZACIONAL
}

\section{THE MEASUREMENT OF INTELLECTUAL CAPITAL: ANALYSIS OF THE APPROPRIATE MODEL IN THE ORGANIZATIONAL PRAXIS}

\author{
Recebimento: 30/06/2019 - Aceite: 06/01/2019 - Publicação: 28/02/2020 \\ Processo de Avaliação: Double Blind Review
}

\author{
Alexandre André Feil ${ }^{1}$ \\ Doutor em Qualidade Ambiental pela Universidade Feevale (FEEVALE) \\ Professor do Mestrado Profissional Universidade do Vale do Taquari (UNIVATES) \\ alexandre.feil1@gmail.com
}

\section{RESUMO}

O conhecimento, na atualidade, é um elemento essencial que contribui na geração de vantagens competitivas e riquezas às organizações. Neste contexto, este estudo objetiva identificar e mensurar o capital intelectual pelo método adequado à organização de construção civil e atividades afins. A metodologia centra-se na abordagem quali-quantitativa e descritiva, com o auxílio da pesquisa documental e da entrevista não estruturada. A unidade de análise compreende uma indústria e comercio de materiais, argamassa para construção e rodovias asfálticas, denominada de Alfa. Os modelos de capital intelectual utilizados neste estudo, em função das limitações de informações disponíveis na organização, compreendem os métodos de capitalização de mercado (Market-to-book Ratio, Market Value Added e Tobin's q) e os métodos scorecards (intellectus, Skandia Navigator e Stewart). Os resultados revelam que os métodos de capitalização de mercado são de avaliação rápida e simples, em função disto são inexatos e ineficientes; e os métodos scorecards são complexos e lentos para a mensuração e avaliação do capital intelectual, porém abrangem maior amplitude e profundidade. Neste sentido, conclui-se que o método mais adequado para a mensuração e análise do capital intelectual na Alfa é o Skandia Navigator, pois abrange um conjunto de indicadores e seu resultado apresenta valores absolutos e de razão que auxiliam no processo de gestão interno e externo.

Palavras Chave: Métodos de capitalização de mercado; Métodos scorecards; Gestão; Mensuração.

\section{ABSTRACT}

Knowledge, at the present time, is an essential element that contributes in the generation of competitive advantages and riches to the organizations. In this context, this study aims to identify and measure intellectual capital by the appropriate method to the civil construction organization and related activities. The methodology focuses on the quali-quantitative and

\footnotetext{
${ }^{1}$ Autor para correspondência: Universidade Vale do Taquari (UNIVATES): Hoffmeister, $500 \mid$ Zona Industrial Norte, Campo Bom, RS - CEP 93700-000- Brasil.
} 
descriptive approach, with the aid of documentary research and unstructured interviewing. The analysis unit comprises an industry and trade in materials, mortar for construction and asphalt roads, known as Alfa. The models of intellectual capital used in this study, based on the limitations of information available in the organization, include the market capitalization methods (Market-to-book Ratio, Tobin's q and the scorecard methods (intellectus, Skandia Navigator and Stewart). The results show that market capitalization methods are quick and simple to evaluate, because of this they are inexact and inefficient; and the scorecard methods are complex and slow for the measurement and evaluation of intellectual capital, but they cover greater breadth and depth. In this sense, it is concluded that the most appropriate method for the measurement and analysis of intellectual capital in Alfa is Skandia Navigator, since it covers a set of indicators and its result presents absolute values and reason that aid in the process of internal and external management.

Keywords: Market capitalization methods. Scorecard methods. Management. Measurement.

\section{INTRODUÇÃO}

O conhecimento é considerado uma fonte essencial às organizações, em nível global, que auxilia na geração de vantagens competitivas e riquezas. $\mathrm{O}$ fator humano, entendido como um recurso intangível, é considerado precípuo na geração de valor à organização por meio da inteligência e considerado uma ferramenta inovadora e estratégica no âmbito corporativo (GONZÁLEZ; CALZADA; HERNÁNDEZ, 2017).

O capital intelectual indica o valor acumulado relativo ao conhecimento ou conjunto de ativos intangíveis (CAMPOS et al., 2008) e que permitem a operacionalização das atividades organizacionais com o potencial de transformar ideias em novos produtos ou serviços (MONAGAS-DOCASAL, 2012).

O capital intelectual é formado pela combinação do capital humano, estrutural e relacional, neste caso, percebe-se a complexidade e a multiplicidade de questões vinculadas a sua mensuração (KAMIŃSKA; PARKITNA; SIAŁKOWSKA, 2017). O capital humano relaciona-se com os conhecimentos, experiências e habilidades que são utilizados e incorporados pelos indivíduos nas organizações (SUBRAMANIAM; YOUNDT, 2005). O estrutural é o conhecimento relativo ao banco de dados, patentes, manuais, sistemas, experiências, gestão, e a cultura no âmbito da organização (YOUNDT; SUBRAMANIAM; SNELL, 2004). E o capital relacional abrange o cliente, fornecedor, parceiros de Pesquisa e Desenvolvimento (P\&D), investidor e a sociedade em geral (BLANKENBURG, 2018).

A quantificação do capital intelectual, abrangendo o humano, estrutural e relacional, é considerada complexa e exige recursos financeiro significativo e, apesar disso, seus resultados podem ser incertos (SVEIBY, 2010). Portanto, a medição de fenômenos sociais 
não é possível com uma ferramenta que se assemelha a precisão científica, sendo assim, necessitam de proxies ( $\mathrm{R}$, euros, indicadores, entre outros) para sua mensuração. Este fato pode tornar a quantificação frágil e aberta a manipulações.

Os modelos de mensuração do capital intelectual existentes na literatura são distintos em relação ao contexto no qual são aplicados, ou seja, quanto aos ativos abrangidos e pela seleção do conjunto de indicadores (VAZ et al., 2014). Neste sentido, torna-se difícil a definição de um método específico para a mensuração do capital intelectual, pois os métodos disponíveis na literatura possuem diferentes perspectivas na geração de valor a organização (KAMIŃSKA; PARKITNA; SIAŁKOWSKA, 2017). Fijałkowska (2012) enfatiza que na definição do método de mensuração adequado em determinada organização torna-se necessário considerar os seguintes fatores: a) a finalidade da mensuração e a utilização do resultado gerado; b) a disponibilidade das informações necessárias e a amplitude; c) a forma de coleta das informações e dados; e d) o custo-benefício na aquisição das informações.

Neste contexto, este estudo objetiva identificar e mensurar o capital intelectual de uma organização de construção civil e atividades afins. Os estudos que contribuem com a literatura empírica sobre o tema são escassos (MENTION; BONTIS, 2013), existem poucos estudos que fornecem instrumentos objetivos para quantificação do capital intelectual (VIDOTTO et al., 2017), a mensuração do capital intelectual ainda necessita de um longo caminho de pesquisa (RAMÍREZ; MANZANEQUE; PRIEGO, 2017). Neste sentido, este estudo contribui com a teoria e a prática relacionada a mensuração do capital intelectual, na escolha do método, na utilização das informações geradas e as suas fragilidades ou limitações.

\section{REFERENCIAL TEÓRICO}

\subsection{CAPITAL INTELECTUAL}

O capital intelectual representa um bem intangível que possui o atributo de gerar riqueza as organizações por meio da combinação de conhecimento, informação e experiências (GONZÁLEZ; CALZADA; HERNÁNDEZ, 2017). Manzaneque, Ramírez e Diéguez-Soto (2017) complementam que este capital abrange os empregados (experiência, habilidades e conhecimentos) e a reputação da organização (marca, procedimentos e relacionamento com os stakeholders).

Revista ENIAC Pesquisa, Guarulhos (SP), V.9, n.1, fev.- jul. 2020. 
O capital intelectual possui dois focos distintos, a saber, a da contabilidade e da gestão. Em relação ao ponto de vista da contabilidade o capital intelectual é estático, o que implica na sua mensuração e obtém-se a ideia de ativo intangível; já na perspectiva da gestão é dinâmico e visto como vantagem competitiva organizacional e seu foco é externo (BLANKENBURG, 2018). Diante disto, a perspectiva da contabilidade e da gestão não podem ser segregados, pois se complementam mutuamente no processo organizacional sob uma visão holística (HUSSINKI et al., 2017).

Os componentes do capital intelectual, em especial, são definidos pelo (HUSSINKI et al., 2017): a) capital humano: refere-se aos funcionários e seus conhecimentos, educação, experiências, capacidades, habilidades, características, entre outros; b) Estrutural ou Organizacional: vincula-se a capacidade organizacional, sistemas, softwares utilizados no armazenamento, organização, apresentação do capital intelectual, entre outros; e c) relacional: está contido na forma como as pessoas, clientes, fornecedores, acionistas, entre outros, estão conectadas nas organizações e o resultado quando deixa de fazer parte deste quadro, pois estes agentes influenciam na reputação e imagem da organização.

O capital humano é considerado o elemento central do capital intelectual (MENTION; BONTIS, 2013). Sendo assim, em função das características específicas de cada indivíduo, é difícil de imitação e deve ser percebido como estratégico (recurso chave) para que a organização permaneça na vanguarda, além disso, deve ser desenvolvido e mantido na organização (NDINGURI; PRIETO; MACHTMES, 2012). Diante desta importância, as organizações necessitam ser dinâmicas e eficientes na utilização de seus recursos vinculados ao capital intelectual, pois pode considerar-se como uma espécie de alavanca para atingir resultados positivos à organização em longo prazo (VIDOTTO et al., 2017).

\subsection{MODELOS DE MENSURAÇÃO DO CAPITAL INTELECTUAL}

A mensuração do capital intelectual significa a determinação do seu valor que possui à organização e o objetivo vincula-se no melhoramento do desempenho interno (SVEIBY, 2010). Kamińska, Parkitna e Siałkowska (2017) salientam que a essência da mensuração do capital intelectual está vinculada ao conjunto de métricas e indicadores de forma mútua, considerando as suas relações, a influência retribuída e o funcionamento holístico da organização. González, Calzada e Hernández (2017) enfatizam que nenhum método cumpre 
todos os objetivos, sendo assim, ao selecionar algum para apuração do capital intelectual deve-se considerar as especificidades de cada caso.

Os principais modelos de mensuração do capital intelectual correspondem ao Skandia Navigator, Stewart, Market Value Added, Market-to-book Ratio, Tobin's q, Intangible Assets Monitor (Sveiby) e o intellectus. Salienta-se que neste estudo apresenta-se estes modelos específicos, porém a literatura apresenta outros que possuem bases subjetivas para sua mensuração. Sendo assim, optou-se em utilizar os modelos com aderência em apresentar resultados da mensuração em valores e de razão.

O modelo Skandia Navigator foca-se em seis áreas (EDVINSSON, 1997): a) Financeiro: relaciona-se a uma medida da empresa do passado em determinado momento com base nas informações contidas no balanço patrimonial; b) Cliente: vincula-se ao atendimento, relacionamento e satisfação dos clientes; c) humano: centra-se nos funcionários; d) Processo: uso da tecnologia informatizadas para tornar as atividades eficientes; e) renovação; e f) desenvolvimento: centra-se no futuro da organização. A soma destas áreas foco do Skandia Navigator compreendem o valor do capital intelectual de uma organização.

A mensuração destas seis áreas realiza-se por meio de indicadores, e estes são desenvolvidos com base na abordagem tradicional e estratégica e geram valores numéricos (EDVINSSON, 1997). Sendo assim, a síntese das informações de cada área apresenta uma visão equilibrada das dimensões financeiras e não financeiras. Edvinsson e Malone (1998) sugerem 21 indicadores de mensuração absoluta do capital intelectual e 9 índices do coeficiente de eficiência do capital intelectual no processo de medição, porém os indicadores utilizados podem ser distintos destes e adequados a cada atividade e porte organizacional. As vantagens deste modelo favorecem a incorporação de elementos financeiros e pode ser adaptado a qualquer organização; entretanto, as desvantagens aderem-se a dificuldade de aplicação da mesma metodologia em distintos tipos de capital intelectual e não avalia as inter-relações (sinergias) entre as áreas (GOGAN, 2014).

O modelo Stewart centra-se em quatro grupos, a saber (STEWART, 1997): a) Razão valor de mercado/valor contábil; b) Capital de clientes; c) Capital estrutural; e d) Capital humano. Estes grupos são mensurados tendo o auxílio de indicadores os quais quando definidos devem ser observados os princípios da simplicidade - a sugestão que cada grupo tenha, em média, três indicadores -, estrategicamente importante e avalie atividades que 
produzem riqueza intelectual. A apresentação dos resultados do modelo Stewart pode ser apresentada por um gráfico circular, em forma de radar, pois beneficia o agrupamento das medidas de razão, percentual, valores absolutos, entre outros (STEWART, 1997). Além disso, devem ser definidas metas para cada um dos indicadores, pois estes limitam a parte externa do gráfico radar.

O modelo Market Value Added é o resultado da diferença entre o valor de mercado da organização e seu valor contábil (DAI; DUSERICK; DAI, 2005). A vantagem deste modelo é a simplicidade e, além disso, se o valor de mercado é menor que o valor contábil, significa que a organização não possui valor relacionado ao capital intelectual. Mouritsen, Larsen e Bukh (2001) salientam que a diferença do valor de mercado e contábil consiste no valor do capital intelectual, porém, entende que o valor de mercado e contábil não podem ser considerados um capital intelectual. Além disso, esta equação acarretaria problemas a contabilidade em função de alterações nos critérios contábeis que podem refletir no capital intelectual e não mensura de forma explícita o nível de conhecimento, habilidade e experiência do capital humano.

O modelo Market-to-book Ratio é a divisão do valor de mercado e o valor contábil da organização e promove a comparação dos resultados de empresas do mesmo setor em função da razão (STEWART, 1997). O Market-to-book Ratio evidencia a valorização da organização frente aos dados registrados na contabilidade (SANTANNA; TEIXEIRA; LOUZADA, 2003).

O modelo Tobin's $q$ fornece a relação de valor de mercado em substituição de ativos tangíveis (LINDENBERG; ROSS, 1981). O resultado deste modelo superior a 1 significa que a organização possui valor maior do que o retorno médio dos investimentos (FIJAŁKOWSKA, 2012). Este modelo foi desenvolvido para prever o comportamento de investimentos e, segundo Ghosh e Wu (2007), é adequado para avaliar o capital intelectual e comparar os seus resultados ao longo do tempo, por intermédio de uma série temporal. Fijałkowska (2012) relaciona ao Tobin's $q$ a vantagem da facilitação de apuração e interpretação e permite comparações, já a desvantagem é valer-se da simplicidade em função da complexidade da apuração do custo de reposição vinculados às influencias de variáveis exógenas e de flutuações imprevisíveis.

O Intangible Assets Monitor concentra-se em três grupos de ativos intangíveis, tais como, a competência das pessoas, estrutura interna e estrutura externa, por meio de 
indicadores com características específicas entre as organizações (SVEIBY, 1997). Suas vantagens relacionam-se ao fornecimento de uma imagem holística do capital intelectual e as relações com os principais stakeholders são considerados, já as desvantagens centram na dificuldade na escolha dos indicadores apropriados e pela ausencia da medição na forma numérica do capital intelectual (GOGAN, 2014).

O modelo intellectus objetiva apresentar um quadro ordenado de informações para a reflexão e implementação de iniciativas voltados a gestão intelectual da organização (CAMPOS et al., 2008). A estrutura deste modelo é flexível e adaptável e construída sob a premissa de três blocos de capitais que interagem com a dinâmica organizacional, a saber (BUENO et al., 2011): a) Capital humano; b) capital estrutural; e c) Relacional. Arnosti et al. (2011) sugerem os indicadores utilizados na mensuração do capital intelectual referente ao modelo intellectus, segregados nos três blocos de capitais (humano, estrutural e relacional).

\section{METODOLOGIA}

A abordagem, deste estudo, é quali-quantitativa, pesquisa documental secundária e a entrevista não estruturada. A unidade de análise compreende uma organização que tem como atividade operacional a preparação de argamassa de concreto para construção de prédios, casas, pontes, entre outras, e a construção e reparação de rodovias asfálticas. Esta empresa tem cede na região sul do Brasil, e em função do fornecimento de informações sigilosas optou-se pela não divulgação de sua razão social, e assim, neste estudo denominada de Alfa. A definição desta unidade de análise ocorreu pelo fato de ser uma demanda da própria empresa a mensuração de seu capital intelectual.

O processo de coleta teve como base as informações dos modelos de mensuração do capital intelectual utilizados neste estudo. Os modelos Skandia Navigator, Stewart, Market Value Added, Market-to-book Ratio, Tobin's q e o intellectus foram identificados como aptos a serem aplicados, pois a organização teria a disposição os dados ou informações necessárias para a alimentação dos modelos e posterior mensuração do capital intelectual.

A coleta das informações relacionadas ao tempo de serviço dos funcionários; número de funcionários; horas e valores dos treinamentos; rotatividade de funcionários; cargo de gerencia em função dos funcionários totais; número de clientes novos-antigos; número de patentes; o valor e percentual dos produtos em função do faturamento total; faturamento em 
percentual por município e os investimentos em $R \& D$ foram coletados por meio do software de controle e gestão interno da ALFA, com auxílio dos gestores das áreas de recursos humanos, faturamento e de investimentos.

A rentabilidade da concorrência foi coletada no site da BM\&FBovespa, com base nas informações financeiras disponíveis, a definição das empresas concorrentes realizou-se em função da aproximação da atividade e do porte. As organizações selecionadas relacionam-se a Concretagem de Rodovias do tietê S/A, Ecorodovias Concessões e Serviços S/A, Ecorodovias Infraestrutura e Logística S/A, Empresa ConcRodov do Norte S/A e a Rodovias das Colinas S/A. As informações coletadas destas empresas centram-se no lucro/prejuízo do exercício e o total de investimentos realizados no período.

Os indicadores coletados com base na entrevista não estruturada com os gestores de cada departamento interno da Alfa, foram os seguintes: Índice de motivação dos funcionários/Atitude dos funcionários (Gerente de Recursos Humanos); o desempenho/meta de qualidade e a Eficiência administrativa/receitas (Controller); e o Custo de substituição do banco de dados (Gerente de Tecnologia da Informação). As perguntas realizadas na entrevista foram: a) de 0 a 100, qual o grau de qualidade da empresa, pesando em produtos, clientes e estrutura?; b) de 0 a 100, qual o grau de eficiência administrativa (contrário de erros administrativos)?; c) caso o banco de dados necessitasse ser substituído hoje, quanto custaria?; e d) qual o índice de motivação dos funcionários/atitude dos funcionários?

As informações relacionadas a satisfação dos clientes e do clima organizacional foram coletadas junto aos relatórios de pesquisa que a ALFA mantinha em seu banco de dados, por exemplo, índice de satisfação dos clientes, número de clientes pesquisados, nível de satisfação dos funcionários, entre outros. A tabulação dos dados e indicadores coletados e a aplicação das Equações dos métodos de mensuração de capital intelectual realizou-se com o auxílio do Software Microsoft Office Excel. A comparação e análise dos resultados dos modelos de mensuração do capital intelectual foram realizados com criticidade e vinculados a utilização práxis no cotidiano da ALFA.

Revista ENIAC Pesquisa, Guarulhos (SP), V.9, n.1, fev.- jul. 2020. 


\section{RESULTADOS E ANÁLISES}

\subsection{A MENSURAÇÃO DE CAPITAL INTELECTUAL PELOS MÉTODOS DE CAPITALIZAÇÃO DE MERCADO}

Os modelos que se utilizam de valores numéricos para a mensuração do capital intelectual compreendem o Market-to-book Ratio, Market Value Added e Tobin's q (Figura $1)$.

Figura 1 - Cálculo pelos métodos de capitalização de mercado

$$
\begin{gathered}
\text { Market-to-book Ratio }=\frac{\text { Valor de Mercado }^{1}}{\text { Valor Contábil }}=\frac{450.478 .729,00}{255.487 .748,28}=\mathbf{1 , 7 6} \\
\text { Market Value Added }=450.478 .729,00-255.487 .748,28=\mathbf{1 9 4 . 9 9 0 . 9 8 1 , 0 0} \\
\text { Tobin's } q=\frac{\text { Valor de Mercado de Ativos }}{\text { Custo de Reposição dos Ativos }}=\frac{450.478 .729,28}{179.778 .781,53}=\mathbf{2 , 5}
\end{gathered}
$$

Legenda: ${ }^{1}$ Valor de Mercado = Ativos tangíveis + Ativos intangíveis (MILONE, 2004) Fonte: Elaborado pelo autor.

O Market-to-book Ratio revela que o capital intelectual é igual a 1,76, ou seja, superior a 1. Este resultado revela que o valor do capital intelectual é 1,76 vezes maior que o valor contábil e é indicado para comparar os resultados entre empresas concorrentes ou uma média do setor. O Market Value Added revela que o mercado reconhece um total de R \$ 194.990.981,00 a maior daquele registrado na contabilidade. O resultado de 2,5 do Tobin's $q$ indica que o potencial de valorização relacionado ao capital intelectual é favorável em $150 \%$ em relação ao custo de reposição dos ativos.

Os modelos Market-to-book Ratio, Market Value Added e Tobin's q podem ser uma oportunidade de avaliação rápida e simples do capital intelectual e que pode contribuir com uma visão turva e não exata sobre o valor do capital. Entretanto, a organização pode-se utilizar destes modelos desde que considere as limitações que possuem quanto a forma de mensuração e utilização do processo de gestão empresarial.

\subsection{A MENSURAÇÃO DE CAPITAL INTELECTUAL PELOS MÉTODOS SCORECARDS}

Os modelos de mensuração do Capital Intelectual que se utilizam de indicadores, apresentados nesta subseção, compreendem o intellectus, Skandia Navigator e Stewart. O modelo Intellectus revela que os indicadores do capital humano contribuem com o processo 
de gestão, pois nota-se, por exemplo, que os indicadores podem auxiliar no direcionamento dos esforços empresariais para a melhora do nível de capital intelectual (Figura 2).

Figura 2 - Modelo intellectus

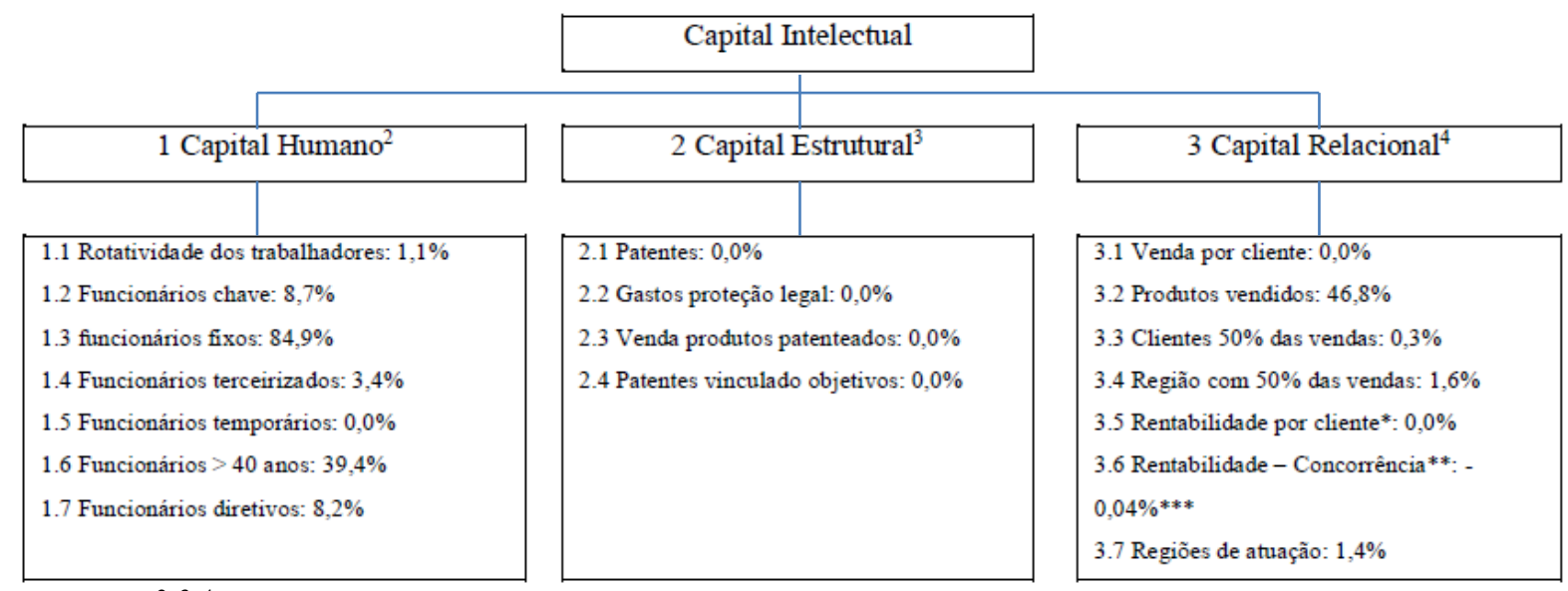

Legenda: ${ }^{2,3,4}$ Anexo 1.

Fonte: Elaborado pelo autor.

As limitações do modelo intellectus relacionam-se a coleta das informações (envolve distintas e diversas áreas), não evidencia o valor absoluto do capital intelectual, os indicadores podem ser distintos em virtude das características específicas da organização, entre outros. Entretanto, apesar destas limitações sua utilização pode auxiliar de forma consistente no processo gerencial para promover o aumento do capital intelectual das organizações e gerar novos resultados econômicos. Esta reflexão vai ao encontro de Monagas-Docasal (2012) ao destacarem que o desempenho organizacional pode ser determinado em "grande parte" pela gestão de seu capital intelectual.

O modelo Stewart apresenta a meta que cada indicador deve atingir (Figura 3) e o valor real (Tabela 1). Estas informações são essenciais para tornar o capital intelectual eficiente, ou seja, demonstra os indicadores que exigem atenção para que sejam adotadas estratégias por meio do processo de gestão.

Revista ENIAC Pesquisa, Guarulhos (SP), V.9, n.1, fev.- jul. 2020. 
Figura 3 - Modelo Stewart

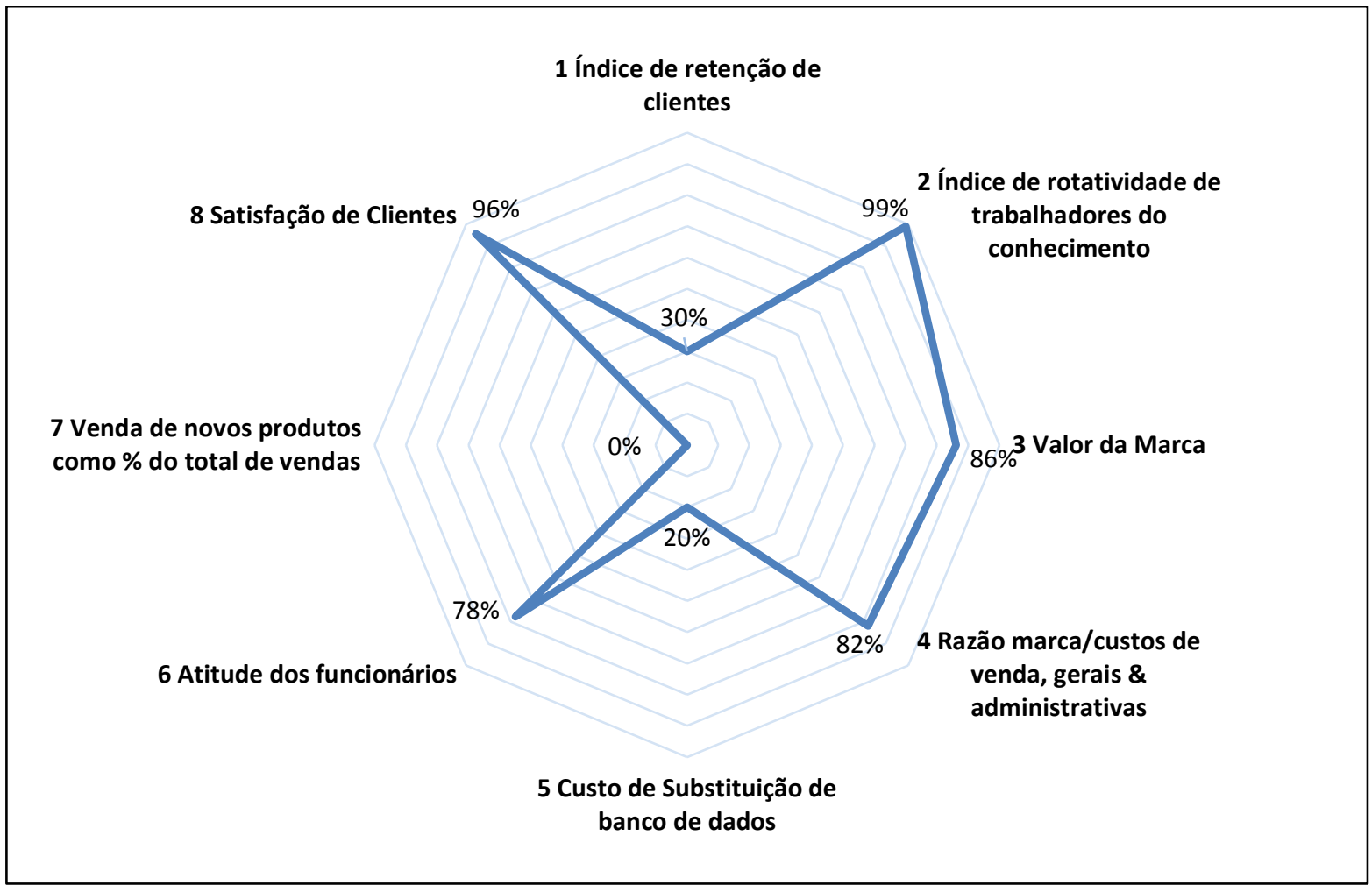

Fonte: Elaborado pelo autor

As limitações do modelo Stewart centram-se na finalidade avaliativa, ou seja, este modelo realiza a avaliação do capital intelectual e não de sua mensuração (não apresenta valores), o que também pode ser visto em Stewart (1998). Nesta lógica, este modelo é indicado no gerenciamento do capital intelectual, onde os gestores podem intervir em situações nas quais as metas não estão sendo atingidas.

Tabela 1 - Modelo Stewart

\begin{tabular}{c|c|c|c|c}
\hline Indicador & Real & Meta & Base (\%) & Observação \\
\hline 1 & 0,03 & 0,10 & 30 & Quanto maior, melhor \\
\hline 2 & 0,01 & 0,00 & 99 & Quanto menor, melhor \\
\hline 3 & $422.049 .967,00$ & $490.000 .000,00$ & 86 & Quanto maior, melhor \\
\hline 4 & 2,46 & 3,00 & 82 & Quanto maior, melhor \\
\hline 5 & $400.000,00$ & $500.000,00$ & 20 & Quanto menor, melhor \\
\hline 6 & 0,70 & 0,90 & 77 & Quanto maior, melhor \\
\hline 7 & 0,00 & 0,01 & 0 & Quanto maior, melhor \\
\hline 8 & 0,86 & 0,90 & 96 & Quanto maior, melhor \\
\hline
\end{tabular}

Fonte: Elaborado pelo autor 
O diferencial do Skandia é a sua amplitude de alcance, pois abrange valores absolutos e de razão por meio de indicadores e, além disso, apura o valor do capital intelectual em valores absolutos (Tabela 2).

Tabela 2 - Modelo Skandia

\begin{tabular}{|c|c|c|c|}
\hline $\begin{array}{c}\text { Indicadores da Mensuração Absoluta do } \\
\text { Capital Intelectual }\end{array}$ & $\mathbf{R} \$$ & $\begin{array}{l}\text { Índice do Coeficiente de Eficiência } \\
\text { do Capital Intelectual }\end{array}$ & $\%$ \\
\hline Receitas de novos negócios & 0,00 & 5.1 Participação de mercado* & 39,1 \\
\hline Investimento em novos mercados & $32.152,90$ & 5.2 Índice de satisfação dos clientes & 85,7 \\
\hline Investimento no setor industrial & $942.605,64$ & 5.3 Índice de liderança & 8,2 \\
\hline Investimento em novos canais & 0,00 & 5.4 Índice de motivação & 70,2 \\
\hline Investimento em TI (vendas) & $194.070,91$ & 5.5 Índice de investimento em $\mathrm{R} \& \mathrm{D}$ & 0 \\
\hline Investimento em TI (Novos equipamentos) & $164.403,73$ & 5.6 Índice de horas de treinamento** & 34,3 \\
\hline Investimento no suporte aos clientes & 0,00 & 5.7 Desempenho de qualidade & 76,8 \\
\hline Investimento no serviço aos clientes & $149.098,24$ & 5.8 Retenção dos empregados & 17,1 \\
\hline Investimento no treinamento de clientes & 0,00 & 5.9 Eficiência administrativa & 60 \\
\hline Despesas com os clientes sem venda & 0,00 & Média do índice de Eficiência & 43,49 \\
\hline Investimento em competência dos empregados & $27.559,25$ & & \\
\hline $\begin{array}{l}\text { Investimento em suporte e treinamento } \\
\text { relativo a novos produtos para os empregados }\end{array}$ & 0,00 & & \\
\hline $\begin{array}{l}\text { Treinamento aos empregados que não } \\
\text { trabalham nas instalações da empresa }\end{array}$ & 0,00 & & \\
\hline $\begin{array}{l}\text { Investimento em treinamento, aos empregados } \\
\text { permanentes em períodos integral }\end{array}$ & $9.733,39$ & & \\
\hline $\begin{array}{l}\text { Programas de treinamento aos empregados } \\
\text { temporários em período integral }\end{array}$ & 0,00 & & \\
\hline $\begin{array}{l}\text { Programas de treinamento aos empregados } \\
\text { temporários de tempo parcial }\end{array}$ & 0,00 & & \\
\hline Investimento em parcerias/joint-ventures & 0,00 & & \\
\hline Upgrades à rede eletrônica de dados & $19.834,00$ & & \\
\hline Investimento na identificação da marca & $3.260,00$ & & \\
\hline Investimento em patente e direito autoral & 0,00 & & \\
\hline Total da mensuração absoluta & 1.542.718,06 & & \\
\hline
\end{tabular}

Fonte: Elaborado pelo autor.

Os indicadores e os índices do Skandia (Tabela 2) revelam que a Alfa apresenta resultados críticos, em especial, aos indicadores relacionados a investimentos no suporte e treinamento de clientes e empregados, e patentes e direito autoral; e dos índices referente a 
liderança, investimentos em R\&D e na retenção de empregados. Estes indicadores e índices devem ser alvos de melhorias por meio de estratégias corporativas, pois compreendem os encalços da Alfa no aumento do capital intelectual. Entretanto, o modelo não segrega as áreas do capital intelectual em humano, estrutural, clientes, entre outros, o que dificulta a identificação das áreas que merecem maior atenção na organização.

O valor absoluto do capital intelectual apurado pelo Skandia sugere um valor de R $\$$ 717.209,63, considerado o valor do conhecimento, experiência, e habilidades, ou seja, o capital intangível da Alfa. O capital intelectual pode ser aumentado com base na análise dos indicadores e índices, pois nestes o gestor pode eleger as prioridades para o momento (Figura $4)$.

Figura 4 - Cálculo do capital intelectual absoluto pelo Skandia

Capital Intelectual $=$ Total da Mensuração Absoluta $\mathrm{x}$ Média do Índice de Eficiência

$$
\text { Capital Intelectual }=1.542 .718,06 \times 43,49 \%
$$

Capital Intelectual $=717.209,63$

Fonte: Elaborado pelo autor.

O modelo Skandia fornece informações úteis no âmbito gerencial e contábil, e podem ser utilizadas no processo de gestão endógeno, divulgação por meio do balanço social e pela famepage empresarial, entre outros. Neste sentido, o capital intelectual quando aplicado e utilizado com eficiência pode contribuir no desempenho empresarial, em especial, por meio da interação e combinação de suas diferentes dimensões, também corroborado por Hussinki et al. (2017), Maditinos, Šević e Tsairidis (2010) e Jardon e Martos (2012).

O capital intelectual pode ser influenciado pelo capital humano, pois este pode desencadear a eficiência do capital cliente e estrutural, e logicamente o desempenho do negócio, Bontis (1996) denomina esta influência como decisiva. Neste sentido, o capital humano na organizacional é considerado um ativo inestimável, mas quando não gerenciados com eficiência podem representar, segundo Stewart (1997), apenas um gasto ou custo.

\section{CONSIDERAÇÕES FINAIS}

Os resultados revelam que a mensuração do capital intelectual da Alfa pode ser realizada por meio de duas formas: a) pelos métodos de capitalização de mercado: que abrange o Market-to-book Ratio, Market Value Added e Tobin's q; e b) pelos métodos 
scorecards: que incluem o intellectus, Skandia Navigator e Stewart. Estes métodos foram apurados em função da disponibilidade de informações da organização, sendo que os demais métodos não foram apurados em detrimento das características específicas da Alfa.

Os métodos de capitalização de mercado podem ser utilizados para avaliações rápidas e simples do capital intelectual por meio de valores absolutos ou razões. Entretanto, os resultados são considerados inexatos e que não avaliam a amplitude de abrangência do capital intelectual da organização. Os métodos scorecards utilizam-se de um conjunto de indicadores para mensurar o capital intelectual, sendo assim, contribuem com maior gama de consistência em função da amplitude e clareza quando comparados com os métodos de capitalização de mercado.

O método de mensuração do capital intelectual mais adequado para a Alfa vinculase ao Skandia, pois compreende valores absolutos e de razão na mensuração do capital intelectual. Os valores de razão podem ser utilizados no processo de gestão interno e externo para melhorar o nível de capital intelectual da Alfa; e o valor absoluto do capital intelectual pode ser registrado no Balanço Patrimonial e evidenciar uma valorização patrimonial da organização. Salienta-se que esta análise corrobora com as necessidades da Alfa, mas que outras organizações podem ter distintas necessidades de mensuração e análise do capital intelectual e que outros métodos podem contribuir com maior eficiência.

As limitações deste estudo vem ao encontro das informações disponíveis para coleta na Alfa, pois este fato limitou a aplicação dos demais métodos de mensuração do capital intelectual em termos de razão e valor absoluto apresentados na literatura, por exemplo, modelo de Sveiby, Technology Broker - Brooking, Straiotto, Heurístico, The Value Explorer, Intellectual Capital Benchmarking System, The Value Chain Scoreboard, entre outros. Os estudos futuros podem abarcar a aplicação práxis dos modelos ora citados para avaliar sua utilização e contribuição em termos gerenciais às corporações. Além disso, os modelos que utilizam um conjunto de indicadores devem passar por um processo de revitalização das variáveis, pois as organizações podem apresentar características distintas, dependendo sua atividade, localização, entre outros, que necessitam de variáveis específicos para a mensuração e avaliação do capital intelectual.

Revista ENIAC Pesquisa, Guarulhos (SP), V.9, n.1, fev.- jul. 2020. 


\section{REFERÊNCIAS}

ARNOSTI, J. C. M.; NEUMANN, R.; OLIVEIRA, E. D.; YOMURA, N. Capital Intelectual: Reconhecimento e Mensuração. 1.ed. Curitiba: Juruá, 2011.

BLANKENBURG, K. A Conceptual Framework of Intellectual Capital. In: BLANKENBURG, K. (Org.) Intellectual Capital in German Non-profit Organisations. Springer, Cham, p. 9-47. 2018.

BONTIS, N. Intellectual capital: an exploratory study that develops measures and models. Management Decision, v. 36, n. 2, p. 67-76, 1998. Disponível em: <https://doi.org/10.1108/00251749810204142>. Acesso em 2/2/2019.

BUENO, E. et al. Modelo intellectus: medición Y gestión del capital intelectual. Documents Intellectus, IADE, Universidad Autonoma de Madrid, Madrid. 2011.

CAMPOS, E. B.; SÁNCHEZ, M. P. S.; MORENO, C. M. Génesis, concepto y desarrollo del capital intelectual en la economía del conocimiento: Una reflexión sobre el Modelo Intellectus y sus aplicaciones. Estudios de economía aplicada, v. 26, n. 2, p. 3-24, 2008. Disponível em: $\quad<$ http://capitalintelectual.egc.ufsc.br/wpcontent/uploads/2016/05/2008_Bueno_G\%C3\%A9nesis-concepto-y-desarrollo-del-CI$\underline{1 . p d f}>$ Acesso em 2/8/2019.

CHEN, L.; ZHAO, X. On the Relation between the Market-to-Book Ratio, Growth Opportunity, and Leverage Ratio. Working paper series, 2006.

DAI, Z.; DUSERICK, F.; DAI, L. Achieving competitiveness by organizational learning: Strategy, transformation and measurement. Issues in Information Systems, v. 6, n. 2, p. 147-153, 2005. Disponível em: < https://iacis.org/iis/2005/Dai_Duserick_Dai.pdf > Acesso em $2 / 8 / 2019$.

EDVINSSON, L. Developing intellectual capital at Skandia. Long range planning, v. 30, n. 3, p. 366-373, 1997. Disponível em: <http://capitalintelectual.egc.ufsc.br/wpcontent/uploads/2016/05/7-edvinsson.pdf> Acesso em 2/8/2019.

EDVINSSON, L.; MALONE, M. S. Capital Intelectual: descobrindo o valor real de sua empresa pela identificação de seus valores internos. São Paulo: Makron Books, 1998.

FIJAŁKOWSKA, J. Analiza porównawcza wybranych metod pomiaru i wyceny kapitału intelektualnego. Zarządzanie i Finanse, v. 3, n. 1, p. 415-525, 2012. Disponível em: < http://bazekon.icm.edu.pl/bazekon/element/bwmeta1.element.ekon-element$\underline{000171246013>}$ Acesso em 2/8/2019.

GHOSH, D.; WU, A. Intellectual capital and capital markets: additional evidence. Journal of Intellectual Capital, v. 8, n. 2, p. 216-235, 2007. Disponível em: $<$ https://ah.nccu.edu.tw/item?item_id=54473 > Acesso em 2/8/2019. 
GOGAN, M. L. An innovative model for measuring intellectual capital. Procedia-Social and Behavioral Sciences, v. 124, p. 194-199, 2014. Disponível em: <https://cyberleninka.org/article/n/1004668 >. Acesso em 2/8/2019.

GONZÁlEZ, E. V.; CALZADA, M. A. H.; HERNÁNDEZ, B. C. S. Mexico's industrial sector companies: A measurement of intellectual capital and its impact on financial performance. Contaduría y Administración, v. 62, n. 1, p. 184-206, 2017. Disponível em: $<$ https://ideas.repec.org/a/nax/conyad/v62y2017i1p184-206.html > Acesso em 2/8/2019.

HUSSINKI, H.; RITALA, P.; VANHALA, M.; KIANTO, A. Intellectual capital, knowledge management practices and firm performance. Journal of Intellectual Capital, v. 18, n. 4, p. 904-922, 2017. Disponível em: <https://lutpub.lut.fi/handle/10024/159996> Acesso em 2/8/2019.

JARDON, C. M.; MARTOS, M. S. Intellectual capital as competitive advantage in emerging clusters in Latin America. Journal of Intellectual Capital, v. 13, n. 4, p. 462-481, 2012. Disponível em: <https://www.emerald.com/insight/content/doi/10.1108/14691931211276098/full/html?ski pTracking=true $>$ Acesso em 2/8/2019.

KAMIŃSKA, A. M.; PARKITNA, A.; SIAŁKOWSKA, S. Intellectual Capital-Measuring the Immeasurable and Reporting. In: Information Systems Architecture and Technology: Proceedings of 37th International Conference on Information Systems Architecture and Technology-ISAT 2016-Part IV. Springer International Publishing, 2017. p. 79-93. Disponível em: <https://doi.org/10.1007/978-3-319-46592-0_7> Acesso em 2/8/2019.

LINDENBERG, E. B.; ROSS, S. A. Tobin's q ratio and industrial organization. Journal of business, v. 54, n. 1, p. 1-32, 1981. Disponível em: 〈http://dx.doi.org/10.1086/296120> Acesso em 2/8/2019.

MADITINOS, D., ŠEVIĆ, Z. AND TSAIRIDIS, C. Intellectual capital and business performance: an empirical study for the Greek listed companies. European Research Studies Journal, v. 13, n. 3, p. 145-167, 2010.

MANZANEQUE, M.; RAMÍREZ, Y.; DIÉGUEZ-SOTO, J. Intellectual capital efficiency, technological innovation and family management. Innovation, v. 19, n. 2, p. 167-188, 2017.

MENTION, A.; BONTIS, N. Intellectual capital and performance within the banking sector of Luxembourg and Belgium. Journal of Intellectual capital, v. 14, n. 2, p. 286-309, 2013. Disponível em: $\quad$ http://capitalintelectual.egc.ufsc.br/wpcontent/uploads/2016/05/Intellectual-capital-and-performance-within-the-banking-sectorof-Luxembourg-and-Belgium.pdf> Acesso em 2/8/2019.

MILONE, M. C. M. Cálculo do valor de ativos intangíveis: uma metodologia alternativa para a mensuração do valor de marcas. Tese (Doutorado em Administração) - Universidade de São Paulo, São Paulo, 2004. 
MONAGAS-DOCASAL, M. El capital intelectual y la gestión del conocimiento. Ingeniería Industrial, v. $33, \quad$ n. 2 , p. 142-150, 2012. Disponível em: <http://rii.cujae.edu.cu/index.php/revistaind/article/view/422> Acesso em 2/8/2019.

MOURITSEN, J.; LARSEN, H. T.; BUKH, P. N. Valuing the future: intellectual capital supplements at Skandia. Accounting, Auditing \& Accountability Journal, v. 14, n. 4, p.399-422, 2001. Disponível em: $<$ http://www.pnbukh.com/Files/Files/Udgivne\%20artikler/AAAJ\%202001.pdf2> Acesso em $2 / 8 / 2019$.

NDINGURI, E.; PRIETO, L.; MACHTMES, K. Human capital development dynamics: The knowledge based approach. Academy of Strategic Management Journal, v. 11, n. 2, p. 121-136, 2012.

RAMÍREZ, Y.; MANZANEQUE, M.; PRIEGO, A. M. Formulating and elaborating a model for the measurement of intellectual capital in Spanish public universities. International Review of Administrative Sciences, v. 83, n. 1, p. 149-176, 2017. Disponível em: $<$ https://journals.sagepub.com/doi/abs/10.1177/0020852315575168 > Acesso em 2/8/2019.

SANTANNA, D. P.; TEIXEIRA, A. J. C.; LOUZADA, L. C. A relação entre market-tobook equity e lucros anormais no mercado de capitais no Brasil. In: XXVII ASSOCIAÇÃO NACIONAL DE PÓS-GRADUAÇÃO E PESQUISA EM ADMINISTRAÇÃO ENANPAD, 2003, Atibaia(SP). Anais... Atibaia(SP), 2003.

STEWART, T. Intellectual Capital: The new wealth of organizations. Nicholas Brealey Publishing, Business Digest, New York. 1997.

STEWART, T. A. Capital intelectual: A nova vantagem competitiva das empresas. Rio de Janeiro: Campus: 1998.

SUBRAMANIAM, M.; YOUNDT, M. A. The influence of intellectual capital on the types of innovative capabilities. Academy of Management journal, v. 48, n. 3, p. 450-463, 2005. Disponível

em: $<$ https://www.bc.edu/content/dam/files/schools/csom_sites/faculty/pdf/intellectualcapitala mj2005paper.pdf $>$ Acesso em 2/8/2019.

SVEIBY, K. A. R. L. E. The intangible assets monitor. Journal of Human Resource Costing \& Accounting, v. 2, n. 1, p. 73-97, 1997. Disponível em: $<$ https://www.sveiby.com/files/pdf/the-intangible-assets-monitor.pdf $>$ Acesso em 2/8/2019.

SVEIBY, K. E. Methods for Measuring Intangible Assets. 2010. Disponível em: <http://www.sveiby.com/files/pdf/intangiblemethods.pdf >. Acesso em: 8 jan. 2018.

VAZ, C. R.; ROCHA, P. R. Z.; WERUTSKY, V. D. B. G.; SELIG, P. M.; MORALES, A. B. T. Modelos de mensuração do capital intelectual para tomada de decisão e variáveis de desempenho. Iberoamerican Journal of Industrial Engineering, v. 6, n. 11, p. 245-260, 2014. 
$\langle$ http://incubadora.periodicos.ufsc.br/index.php/IJIE/article/view/3060>. Acesso em: 8 jan. 2018.

VIDOTTO, J. D. F.; FERENHOF, H. A.; SELIG, P. M.; BASTOS, R. C. A human capital measurement scale. Journal of Intellectual Capital, v. 18, n. 2, p. 316-329, 2017.

YOUNDT, M. A.; SUBRAMANIAM, M.; SNELL, S. A. Intellectual capital profiles: An examination of investments and returns. Journal of Management studies, v. 41, n. 2, p. 335-361, 2004. Disponível em: 〈https://psycnet.apa.org/record/2004-11670-006〉. Acesso em: 8 jan. 2018.

Apêndice A - Cálculos relativos a Figura 4 do modelo intellectus

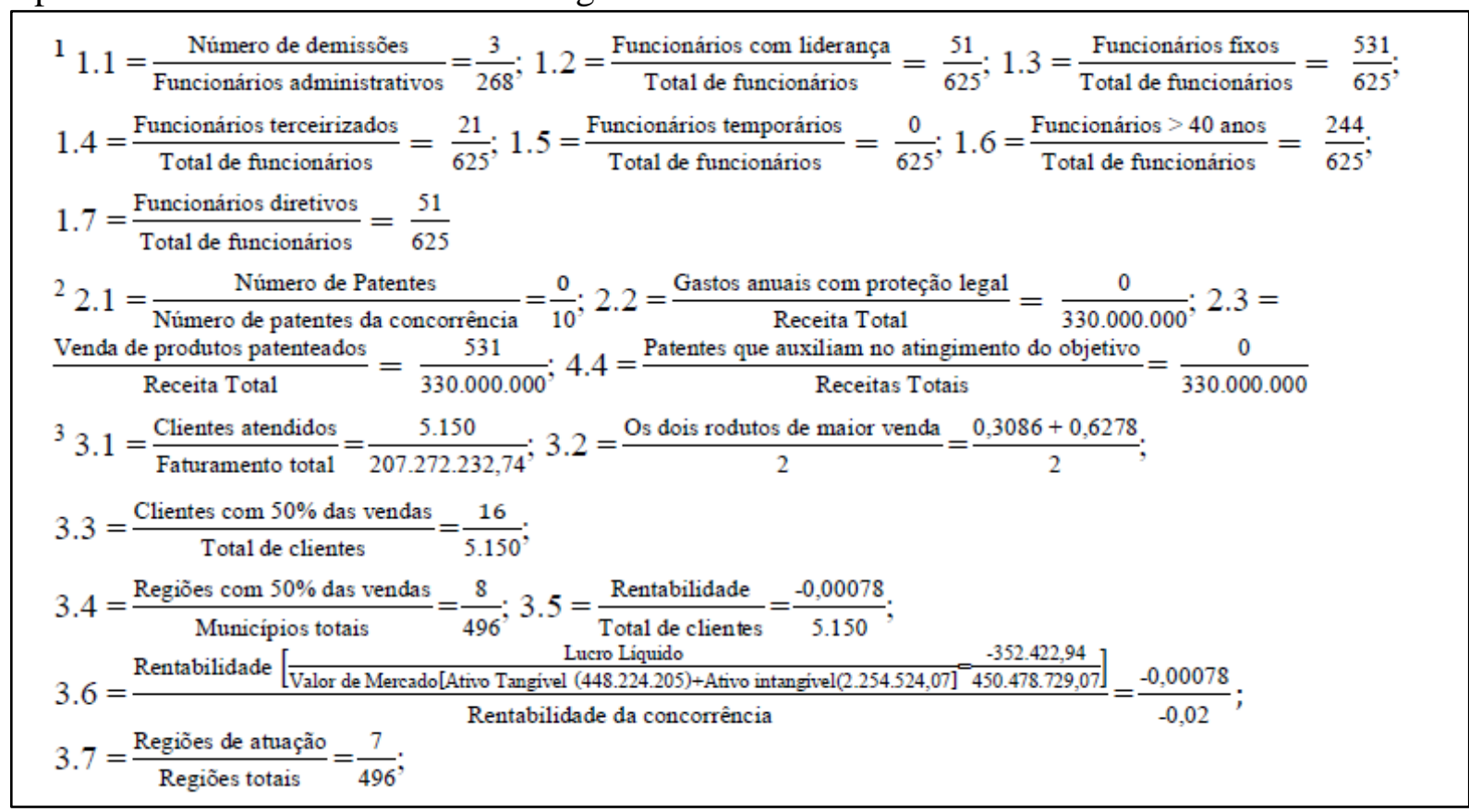

